\title{
INTRACARDIAC THROMBOSIS IN THE CAPE MOUNTAIN ZEBRA
}

\author{
G. F. BATH \\ Regional Veterinary Laboratory \\ Middelburg, Cape Province \\ 5900
}

The Cape mountain zebra (Equus zebra zebra) is one of the rarest species of mammals in South Africa, and is threatened with extinction. At present there are less than 200 in existence, of which approximately 160 occur in the Mountain Zebra National Park near Cradock.

Because of the rarity of the species and the undesirable concentration of the majority in an area of only $6536 \mathrm{ha}$, a post-mortem examination is performed, if possible, on all animals to establish cause of death with the purpose of preventing large-scale mortalities. This is done even if the carcass is in a fairly advanced state of decomposition. Amongst the examinations so performed were two zebra which were believed to have died as a result of intraventricular thrombosis. The rarity of this condition and of the Cape mountain zebra makes a report on these cases necessary.

A two year old stallion in fair condition was found dead without any premonitory symptoms being observed. The carcass was not badly decomposed and the macroscopic pathological lesions observed were peripheral congestion, ascites, hydrothorax, subserosal oedema of the diaphragm, splenic atrophy, severe verminosis and what was believed to be mild hepatic fibrosis and lobar pneumonia. A large arborescent thrombotic body in the right ventricle was at the time believed to be an incidental post-mortem finding. The body was rootlike, with processes 5 $\mathrm{cm}-10 \mathrm{~cm}$ long, dull red and loosely adherent to the wall of the ventricle. On microsopic examination the diagnosis of lobar pneumonia and of hepatic fibrosis was not confirmed. The lesions observed consisted of severe congestion and oedema of the lungs and degenerative lesions and oedema of the liver. In the light of this information the ventricular thrombus became more significant. The following internal parasites were identified:

Tapeworms: Anaplocephala perfoliata

Roundworms: Cylicocyclus auriculatum

Triodontophorus serratus

Trichonema spp.

Insects: Gasterophilus nasalis

Gasterophilus pecorum 
Strongyles (4th stage) were identified in lessons from the wall of the caecum.

A second post-mortem examination was performed on a six year old mare in fair condition. No history was supplied. The carcass was badly decomposed but the following lesions were still discernable: severe small strongyle infestation, severe congestion of the lungs, and an intraventricular thrombus. The thrombus was firmly adherent to the right ventricular septum over about two square centimetres. It was a digitate body resembling the seaweed kelp, and some of the numerous fronds measured over 10 centimetres. The thrombus was dull, partly red and partly yellow-white, had an irregular surface and had a rubbery consistency. Due to the advanced state of decomposition no specimens of organs were taken for microscopic examination although the thrombus was preserved. Unfortunately the specimen was mislaid subsequently. A diagnosis of intraventricular thrombosis with consequent heart failure was made.

The prominent lesions in both cases were intraventricular thrombosis and severe congestion of the lungs as well as severe verminosis. Peripheral congestion, ascites, hydrothorax and subserosal oedema was also observed in the stallion, and congestion and oedema were confirmed microscopically. The evidence, admittedly not complete, points to death due to heart failure as a result of a very large thrombus in the right ventricle interfering with the efficiency of heart action. Both animals died during cold weather and this probably contributed to strain on the heart.

The cause and pathogenesis of the thrombi poses a much more difficult problem. The most obvious likelihood is intravascular parasitism, which gives rise to similar lesions. Examination of the thrombus in the mare would have thrown much light on the matter.

McCully, Kruger, Basson, Ebedes and Van Niekerk (1969) dealt at length with Delafondiasis in Burchell's zebra (Equus burchelli) and the vascular lesions encountered in branches of the portal vein and in the pulmonary and anterior mesenteric arteries. There is therefore a likelihood that one of the strongyles could have been responsible for the formation of the thrombi. Another possibility is that of vascular myiasis, similar to that seen in uitpeuloogsiekte (Basson 1962). At this stage, however, the aetiology remains purely speculative.

\section{REFERENCES}

BASSON, P. A. 1962. Studies on specific oculo-vascular myiasis of domestic animals (uitpeuloog). III. Symptomatology, pathology, aetiology and epizootiology. Onderstepoort J. vet. Res. 29:211-240. McCULlY, R. M., S. P. KRUGER, P. A. BASSON, H. EBEDES and J. W. VAN NIEKERK. 1969. Strongylidoses: Delafondiasis in the zebra. OnderstepoortJ. vet. Res. 36:105-128. 